\title{
Individual differences in metacognition: Evidence against a general metacognitive ability
}

\author{
WILLIAM L. KELEMEN \\ University of Missouri, St. Louis, Missouri \\ PETER J. FROST \\ Rivier College, Nashua, New Hampshire \\ and \\ CHARLES A. WEAVER III \\ Baylor University, Waco, Texas
}

\begin{abstract}
Individual differences in metacognitive accuracy are generally thought to reflect differences in metacognitive ability. If so, memory monitoring performance should be consistent across different metacognitive tasks and show high test-retest reliability. Two experiments examined these possibilities, using four common metacognitive tasks: ease of learning judgments, feeling of knowing judgments, judgments of learning, and text comprehension monitoring. Alternate-forms correlations were computed for metacognitive accuracy (with a 1-week interval between tests). Although individual differences in memory and confidence were stable across both sessions and tasks, differences in metacognitive accuracy were not. These results pose considerable practical and theoretical challenges for metacognitive researchers.
\end{abstract}

The nature of memory monitoring processes has been studied with increasing interest. Most investigations focus on metacognitive accuracy, the relationship between metacognition and future memory performance. There is now a broad base of empirical observations confirming the accuracy of such judgments, with a wide variety of tasks (see Metcalfe \& Shimamura, 1994; Nelson, 1992; Reder, 1996). Investigators in the field have begun to move toward a synthesis of these findings; indeed, several theoretical accounts of metacognitive performance have been proposed (Koriat, 1993, 1994; Metcalfe, Schwartz, \& Joaquim, 1993; Nelson \& Narens, 1990; Reder \& Schunn, 1996).

Memory monitoring can be addressed in a variety of domains, but most experimental work has focused on college students performing verbal learning tasks. Researchers typically collect a subjective judgment of memory accuracy-a confidence rating, a prediction of future performance, or a rating of item difficulty -in addition to the memory task itself. This basic procedure has been em-

This work was supported by a Baylor University Research Council award to C.A.W. Portions of these data were presented in November 1997 at the annual meeting of the Psychonomic Society, Philadelphia. The authors thank Asher Koriat, Ruth Maki, Tom Nelson, and Roddy Roediger for insightful comments on an earlier version of this manuscript. The authors also thank Carolina Ferrari, Constanza Ferrari, and Melanie Witzel for their assistance with data collection. Correspondence should be addressed to C. A. Weaver, III, Department of Psychology and Neuroscience, Baylor University, Waco, TX 76798-7334 (e-mail: charles_weaver@baylor.edu).

-Accepted by guest action editor, Henry L. Roediger, III ployed in a variety of experimental tasks spanning decades: ease of learning judgments (EOLs; Underwood, 1966), judgments of learning (JOLs; Arbuckle \& Cuddy, 1969), feelings of knowing (FOKs; Hart, 1965), and text comprehension monitoring (TCM; Glenberg \& Epstein, 1985, 1987; Glenberg, Sanocki, Epstein, \& Morris, 1987; Glenberg, Wilkinson, \& Epstein, 1982). The first three types of judgments are made before study, after study, or after a retrieval attempt, respectively (Nelson, 1996a; Nelson \& Narens, 1990). Schwartz (1994) has provided a thoughtful review of procedural and theoretical differences between judgments of learning (including both JOLs and EOLs) and FOKs.

TCM is thought to occur "on-line" and probably most resembles a JOL. Predicting future performance for text material requires more sophisticated metacognitive monitoring than tests of basic paired associates or general knowledge questions. Just as JOLs and FOKs are considered theoretically distinct, so studies of TCM form another diverse body of research. We include evidence from all three paradigms in the present discussion. There have been previous efforts to include findings from TCM into the broader verbal learning framework of metacognition (see, e.g., Maki \& Serra, 1992; Weaver \& Bryant, 1995; Weaver, Bryant, \& Burns, 1995). In some cases, similar findings have been obtained in the verbal learning domain and in TCM. We believe that evidence from all three paradigms (JOLs, FOKs, and TCM) can be used to evaluate the concept of general metacognitive ability.

Investigators often assume that differences observed across individuals on metacognitive tasks reflect some 
type of general metacognitive ability - much as performance on different memory tasks is thought to reflect reliable individual differences in memory ability. This assumption is attractive to researchers, and ultimately may be tenable. At present, however, there is surprisingly little empirical support for such global metacognitive ability. Despite the success of past research in isolating numerous factors that influence metacognitive accuracy, there has been no consistent evidence for a general metacognitive ability. This represents a substantial theoretical puzzle for investigators of metacognition. At a minimum, the lack of reliable individual differences highlights significant shortcomings in current methodologies. More seriously, this lack of reliability may indicate a more troubling problem: There may be no unitary, global metacognitive ability.

\section{SOURCES OF INDIVIDUAL DIFFERENCES}

Past research has focused on a number of variables that can produce (or, if uncontrolled, obscure) differences in metacognitive performance between groups. These factors can be classified into three broad categories: task demands, measurement difficulties, or differences in ability. Most research has focused on task demands, which include both stimulus and processing explanations. Several critical issues concerning the measurement of metacognitive performance have also been identified. It is possible - even likely, as some have argued (e.g., Nelson, 1988)-that current measurement procedures do not permit the routine detection of individual differences in metacognitive ability. A few studies, however, have obtained evidence for differences in ability. In these cases, it is unclear whether such differences are best viewed as "state-based"-in which case individual differences in metacognition need not be stable across situations or individuals - or "trait-based"-in which case individual differences should be stable.

\section{Differences in Task Demands}

Task demands can be induced by specific instructions or procedures (processing factors) or by the test materials themselves (stimulus factors). Task demands have been the subject of much scrutiny because they are primarily under the control of the experimenter and more often produce dramatic effects. Some processing factors are so important (e.g., whether the judgment of future memorability occurs before study, after study, or after attempted retrieval) that they are thought to tap distinct aspects of metacognition (Leonesio \& Nelson, 1990) and have sparked different theoretical accounts (see Schwartz, 1994). Although differences in processing can be elicited by altering test stimuli, we nonetheless believe that this is a useful distinction, because processing factors do not necessarily involve stimulus factors.

Processing factors. The importance of processing factors has been well established in verbal learning and TCM studies. Maki, Foley, Kajer, Thompson, and Willert
(1990) found that encoding tasks that increased cognitive effort enhanced metacognitive performance. Participants who read text passages with deleted letters showed better predictive performance than participants who read intact passages. A similar finding was obtained by Nelson, Leonesio, Shimamura, Landwehr, and Narens (1982) using paired associates. They found that additional effort during acquisition (i.e., overlearning of stimuli) was an important determinant of FOK accuracy.

Weaver and Bryant (1995) found that metacognitive accuracy in text comprehension depended on the readability level. Texts that were too easy or too difficult for readers produced lower predictive accuracy relative to texts constructed at an "optimum" reading level. A1though text readability is a stimulus variable, Weaver and Bryant interpreted their findings in terms of processing effort. They proposed that for each individual, there is some intermediate level of cognitive effort that produces maximal metacognitive performance. Related findings have been obtained using paired associates. Begg, Duft, Lalonde, Melnick, and Sanvito (1989) proposed that JOLs are based on the ease of processing. In four experiments, they found that JOLs were most accurate when the prediction task involved the same processing factors as the criterion task, independently of the type of cue used to elicit the prediction.

Test practice can also improve metacognitive performance. Glenberg et al. (1987) found that participants can use self-generated feedback from pretest questions to improve their metacognitive performance on closely related posttest items (Experiments 6-8). Inserting adjunct questions in text increases TCM performance (Glover, 1989; Pressley, Snyder, Levin, Murray, \& Ghatala, 1987; Walczyk \& Hall, 1989); additionally, short-answer adjunct questions can increase metacognitive accuracy more than multiple-choice questions (Pressley, Ghatala, Woloshyn, \& Pirie, 1990). Similar findings concerning the benefits of test practice have been observed using paired associates. King, Zechmeister, and Shaughnessy (1980) demonstrated improved predictive performance for participants who were given tests compared with those given additional study. Apparently, participants used the results of these additional tests as a basis for their JOLs, but the theoretical implications of this finding are confounded because memory performance increased in conjunction with metacognitive performance. Lovelace (1984) found that both additional study and test trials prior to JOL increased predictive accuracy, with spaced presentations increasing JOL accuracy more than massed ones.

The timing of judgments can affect metacognitive accuracy dramatically. It is now well established that delayed JOLs for paired associates are more accurate than immediate JOLs (Nelson \& Dunlosky, 1991). The type of prompt used to elicit the JOLs (i.e., cue-only vs. cue-plustarget prompts) is also critical (Dunlosky \& Nelson, 1992). Recent evidence suggests that this delayed-JOL effect is in part a memory effect (Kelemen \& Weaver, 1997; Spellman \& Bjork, 1992; Weaver \& Kelemen, 1997), but the 
practical advantage of delayed JOLs is substantial, regardless of the theoretical explanation. The finding has been observed even with recognition criterion tasks (Begg et al., 1989; Thiede \& Dunlosky, 1994) and is sensitive to the type of encoding procedures used (e.g., imagery vs. rote rehearsal; Dunlosky \& Nelson, 1994).

Stimulus factors. Stimulus variables refer to differences in metacognitive accuracy produced by systematic variation of the experimental materials. In TCM studies, these include the genre of text (e.g., narrative vs. expository), length, and text readability. In standard verbal learning studies, they include concreteness, relatedness, and range of difficulty for the paired associates. Stimulus factors often induce processing differences (see above), but the latter can also occur without the former.

Several differences in item attributes affect metacognitive accuracy for paired associates. Begg et al. (1989) found that participants provided higher JOL ratings for concrete and common words, even though these factors did not lead to increased recognition performance (Experiment 1). The relatedness of stimuli can also affect memory monitoring accuracy. Rabinowitz, Ackerman, Craik, and Hinchley (1982) used lists of word pairs with varying degrees of association. They found that JOLs were higher for more closely related word pairs than for less closely related words, even when the instructions for encoding successfully increased memory performance for the less closely related words. Dunlosky and Schwartz (1995) also reported that predictions of performance for free recall are based on encoded relational information. Mean JOL ratings were higher for groups of related words than for unrelated words, and the magnitude of item-byitem JOLs increased as participants learned that the stimuli were related.

The overall difficulty and range of stimuli can also affect observed metacognitive accuracy. For example, Schraw and Roedel (1994) found that overconfidence is due to both test-based and person-driven errors. Test difficulty accounted for most of the overconfidence in comprehension monitoring (Experiment 1), and the severity of overconfidence did not change across different tasks matched for difficulty (Experiment 2). Consistent confidence levels across eight distinct domains were also noted by Schraw, Dunkle, Bendixen, and Roedel (1995). In Experiment 1 , participants estimated confidence in their answers to questions in variety of domains (geographical distances, U.S. presidents, caloric value of food, running speed of animals, mathematical word problems, spatial judgments, general knowledge, and reading comprehension). Schraw et al. (1995) found that confidence scores were correlated across tasks, but metacognitive accuracy was inconsistent across domains. When tasks were matched on difficulty, format, length, and inferential demands, metacognitive performance correlated more highly across tasks. This is consistent with Maki and Berry's (1984) earlier finding that "structural" variables such as length, serial position, and hierarchical level of text sections were related to metacognitive performance, but not memory performance.

Even if participants adopt a global confidence level that is appropriate for test difficulty level (e.g., by receiving practice tests or adjunct questions), item-by-item metacognitive accuracy can be impaired if the questions are derived from a restricted range of difficulty. For example, Koriat (1993, p. 634) described a situation in which relative FOK accuracy might be low for a group of very easy items and for a different group of very difficult items. However, if a single measure of FOK accuracy was calculated for both groups combined, relative accuracy could be very high (see Koriat, 1995, for an empirical demonstration of this argument). Similarly, Nelson, Leonesio, Landwehr, and Narens (1986) found that the correlation between FOK judgments and memory performance was higher when questions were more normatively different. Schwartz and Metcalfe (1994) also found that the range of recognition difficulty for general knowledge questions reliably altered metacognitive performance. Thus, when comparing metacognitive accuracy across tasks or populations, investigators should be sensitive to the normative difficulty of items being tested.

\section{Unreliability of Measurement}

Numerous potential difficulties for assessing metacognitive accuracy have been identified (for a review, see Schwartz \& Metcalfe, 1994). One particularly enigmatic topic concerns which measure should be used to assess the relationship between prediction and performance. Difference scores (see, e.g., Hart, 1965; see also the predictive accuracy quotient used by King et al., 1980, and Lovelace, 1984), correlation coefficients [Pearson's $r$, Goodman \& Kruskal's gamma $(G)$, and $\phi]$, and signal detection analyses have all been used to assess metacognitive performance. There is now considerable evidence that the nonparametric $G$ correlation is the best measure of relative metacognitive accuracy (Nelson, 1984, 1996b; Wright, 1996). ' Because $G$ treats only the rank of the underlying distribution of data, the potentially interesting magnitude of judgment differences cannot be determined (Schwartz \& Metcalfe, 1994). Therefore, absolute metacognitive accuracy is often assessed by plotting actual performance as a function of predicted performance (i.e., a calibration curve). This procedure provides an index of overconfidence or underconfidence known as bias. Identical calibration curves can produce different $G$ s, depending on the distribution of judgments (Weaver \& Kelemen, 1997). In addition, processing variables can differentially affect these measures: Koriat (1997) found that practice improves relative accuracy but lowers absolute accuracy. Given that various measures of absolute and relative metacognitive accuracy provide different pieces of information, investigators should consider using multiple measures (Maki, 1998).

Failure to obtain an adequate index of memory performance can produce unreliable measures of metacogni- 
tive accuracy. For example, noise generated by guessing can obscure genuine metacognitive accuracy in predictions of recognition. Participants who monitor their memory perfectly might show imperfect $G$ s due to correct guessing on items they did not actually know. Leonesio and Nelson (1990) sought to minimize this effect by including 19 alternatives on their recognition test, although this solution may not be practical for all types of materials. In TCM studies, it is critical to allow participants ample opportunity to demonstrate their knowledge. Glenberg and his colleagues observed low metacognitive accuracy when one test question was used per text (e.g., Glenberg \& Epstein, 1985, 1987; Glenberg et al., 1987). However, Weaver (1990) demonstrated that metacognitive accuracy for texts could be improved substantially merely by assessing memory with several questions for each text. In short, stable and accurate measures of metamemory require adequate memory assessment.

Are measures of metacognition typically reliable? Maki, Jonas, and Kallod (1994) examined the internal reliability of predictive and posttest judgments for 12 sections of text. They calculated $12 G$ correlations for each participant based on random groups of 6 judgment-test dyads. Cronbach's $\alpha$ was high (above .90) for both pre- and posttest judgments. This finding suggests that $G$ itself is a reliable metacognitive measure, but does not address whether differences between individuals are stable.

When judgments are made repeatedly on the same items, test-retest correlations are quite high. Nelson, McSpadden, Fromme, and Marlatt (1986) observed that the median probability of items presented twice for judgment would receive the same ranking was .93. Costermans, Lories, and Ansay (1992) asked participants to make confidence judgments twice and found a $G$ correlation of .87 for the same set of items. Clearly, reliability computed for judgments on the same items is generally quite high.

Reliability can also be computed for sets of judgments made on distinct items. Alternate-forms and split-half reliabilities have been used to examine whether metacognitive accuracy is consistent for the same metacognitive task using different stimuli. Thompson and Mason (1996) elicited predictions of memory performance for faces, adjectives, and general knowledge questions, and then repeated this procedure 2 weeks later using alternate test forms. They computed $G$ between predictions and actual performance as a measure of metacognitive accuracy during each session. Finally, Spearman $r$ correlations were computed between $G$ s derived from alternate test forms and also from split-halves of each individual test. Only 1 of the 19 reported correlations reached statistical significance at the .05 alpha level.

Nelson (1988) observed a similar lack of reliability using FOKs. In unpublished work, Nelson and his colleagues had previously observed a lack of stability in FOK ratings and postulated that this variability might be due to inadequate set size. Nelson computed split-half reliabilities for FOK accuracy using groups containing 30,70 , or 110 questions. The Spearman $r$ correlations be- tween the two groups ranged from -.18 to -.02 , and none were reliably different from zero. Note that the standard deviations of the FOK accuracy scores were large ( .27 to .14), suggesting that these null results were not due to a restricted range of difficulty. Thus, the only two published studies designed specifically to test the reliability of predictions of performance for different sets of items show a complete lack of reliability (Nelson, 1988; Thompson \& Mason, 1996).

\section{Differences in Ability}

Differences in metacognitive accuracy can be interpreted in terms of a general memory monitoring ability. These differences may reflect a stable cognitive trait, similar to a general comprehension skill, such as that proposed by Gernsbacher and her colleagues (Gernsbacher, Varner, \& Faust, 1990). They found, for example, that comprehension of written and oral stories correlates highly with comprehension of nonverbal picture stories. However, both Nelson (1988) and Thompson and Mason (1996) found no correlation between metacognitive accuracy scores. Moreover, Leonesio and Nelson (1990) found that performance on three distinct metacognitive tasks (EOL, $\mathrm{JOL}$, and FOK) was largely uncorrelated, even for the same set of items. Thus, there is some question as to whether metacognition is best viewed as a stable general trait (like comprehension) or as more of a malleable idiosyncratic state. 2

State-based explanations. Numerous physiological and environmental effects on metacognitive accuracy have been reported. These factors often have differential effects on metacognition and memory performance. Nelson et al. (1990) tested mountain climbers at altitudes up to 20,000 feet and found that metacognition became inaccurate, whereas memory performance was unaffected. Slife and Weaver (1992) reported that severely depressed participants showed both memory and monitoring deficits. Mildly depressed patients showed no memory impairments, but metacognitive accuracy was lower. The converse pattern was found with alcohol: Intoxicated participants showed impaired memory performance, but FOK accuracy was unaffected (Nelson, McSpadden, et al., 1986). Finally, Schraw, Potenza, and NebelsickGullet (1993) found that an increased motivational state induced by incentives for accurate monitoring improved metacognitive performance.

Trait-based explanations. There is some evidence supporting a stable trait view of metacognition. Walczyk and Hall (1989) parsed out "cognitively reflective" versus impulsive children with a Matching Familiar Figures Test. Reflective students were more likely to detect inconsistencies and employed superior metacognitive strategies than impulsive students. ${ }^{3}$ Maki and Berry (1984) found that participants who scored above the median (in test performance) gave higher ratings to items they answered correctly than to those they answered incorrectly. Participants below the median did not. However, participants below the median did show accurate monitoring for im- 
mediate tests, suggesting an interaction between ability and task demands. Maki et al. (1994) found that good readers provided more accurate assessments of past performance (postdictions) than did poor readers, but all participants were poor at predicting their performance. Finally, Schraw et al. (1995) found limited support for a trait-based view of metacognition once task demands were controlled, although this study also used postdictions rather than predictions of performance.

\section{Is There Evidence for a General Monitoring Skill?}

Substantial progress has been made in isolating task demands and measurement procedures that can produce individual differences in metacognitive accuracy. Unfortunately, comparatively little evidence has been found for a general metacognitive skill. Related efforts to link metacognitive accuracy to cognitive ability also have been largely unsuccessful. Individuals can and do monitor their memory in a variety of situations, sometimes extremely well. But where is the evidence for a general monitoring skill?

Metacognition and memory performance. There is no debate over the importance of effective memory monitoring for academic success. However, studies of metacognition in college students have generally failed to show a correlation between metacognitive accuracy and learning ability. This paradox was noted in pioneering work on metacognition: Underwood (1966) found no correlation between EOL accuracy and memory performance. A lack of relationship has been noted by other researchers since then, using various metacognitive tasks. Lovelace (1984) noted that JOL accuracy for paired associates did not relate to memory performance. Kearney and Zechmeister (1989) assessed cognitive ability using a distinct pretest (rather than post hoc test performance), but still found no relationship between EOL accuracy and memory ability. Cull and Zechmeister (1994) postulated that this relationship might be obscured by the use of experimenter-paced study trials. In three experiments with self-paced study, however, they still found that good and poor learners did not use different metacognitive strategies. Finally, similar null results have been observed in TCM studies. In general, learning ability and comprehension do not correlate with metacognitive performance (see Pressley \& Ghatala, 1990, for a review; however, see Maki \& Berry, 1984, and Maki et al., 1994, for exceptions).

Stability between tasks and over time. Few studies have been designed specifically to test the reliability of prospective metacognitive judgments over time (Thompson \& Mason, 1996) or across tasks (Leonesio \& Nelson, 1990), and none have done both. Data also are scarce concerning the reliability of TCM judgments. Glenberg and Epstein (1987) found unstable individual differences in TCM performance over an interval ranging from 1 to 7 days, although this was not their primary concern.
Maki and Swett (1987) found that the correlation between the accuracy of predictive judgments and confidence postdictions for text was not reliable (Pearson $r=$ $.04)$. Given the increasing interest in metacognition, it is surprising that so little attention has been focused on the apparent unreliability of these judgments.

The present study examines these inconsistencies. We investigated the reliability of memory judgments using four common metacognitive tasks: (1) EOL (participants rated the relative difficulty of learning paired associates before study), (2) TCM (participants made judgments concerning their future memory performance on recently read texts), (3) JOL (participants made confidence judgments about future recall of paired associates after study), and (4) FOK (participants rated the likelihood of future recognition for general knowledge questions). These four tasks were designed to be typical examples, based on the substantial literature that exists for each type of judgment. In each condition, ratings about future memory performance were obtained on a set of items, followed by a test on those items. Participants completed each task twice, with a 1-week interval between sessions. This methodology allowed us to examine the stability of individual differences over time within a given task, and also between different metacognitive tasks. Reliable correlations between measures of metacognitive performance in either case would provide evidence for a stable, general monitoring skill.

\section{EXPERIMENT 1}

\section{Method}

Participants. Sixty-six Baylor undergraduates received course credit for participation. All participants were tested in individual cubicles.

Procedures. Stimuli were presented on IBM-compatible PCs using Micro Experimental Laboratory (MEL) software (Schneider, 1988). Participants completed EOL, JOL, FOK, and TCM tasks in two sessions, separated by 1 week. Alternate forms of test stimuli of equal normative difficulty were used for each session.

Ease of learning. Fifteen pairs of Swahili-English word pairs (from Nelson \& Dunlosky's, 1994, norms) were presented one at a time, in random order (e.g., wingu-cloud). While the paired associate was on the screen, participants provided a (self-paced) judgment as to how difficult each pair would be to learn. Instructions prompted participants to select one of six confidence ratings: $0 \%$ (most difficult to learn), $20 \%, 40 \%, 60 \%, 80 \%$, or $100 \%$ (least difficult to learn). Following all EOL ratings, participants studied the paired associates for $6 \mathrm{sec}$ each. Six novel pairs appeared before the 15 critical paired associates as a primacy buffer. These buffer pairs were also studied for $6 \mathrm{sec}$ but did not receive EOL ratings or a future cued-recall test.

After studying all paired associates, participants completed a 3min distractor task. Difficult math problems appeared on the screen one at a time, and participants chose the correct answer from four alternatives. Feedback was provided, and participants were instructed to be as accurate as possible. A self-paced cued-recall test was then administered over the 15 critical paired associates. Any items not answered correctly were presented again for study (again preceded by the buffer items) and subsequently retested. This 
study-test cycle repeated until all items had been answered correctly. The total number of trials required to learn each pair was recorded.

Judgment of learning. Thirty-six unrelated pairs of English concrete nouns (from Paivio, Yuille, \& Madigan, 1968) were studied for $8 \mathrm{sec}$ each (e.g., letter-mountain). The first six pairs served as a primacy buffer and were neither rated nor included in the final cued-recall test. After studying a pair, participants were asked to rate the likelihood of recalling the second word given the first (cue) word (i.e., make a JOL). This JOL prompt consisted of the cue word presented above the 6-point Likert scale described above $(0 \%=$ definitely won't recall, $20 \%, 40 \%, 60 \%, 80 \%, 100 \%=$ definitely will recall ). After studying and rating all paired associates, a 9 -min distractor task was employed. This task required that participants enter as many exemplars as possible from the following three categories, for 3 min each: (1) U.S. states, (2) countries of the world, and (3) U.S. cities. Following this distractor task, a cued-recall test over all 30 paired associates was administered.

Nelson and Dunlosky (1991) found that JOL accuracy is better when judgments are elicited after a delay rather than immediately after acquisition. They suggested that JOLs made at different times (either immediately after study or after a 5-min delay) tap distinct memory processes (however, see Kelemen \& Weaver, 1997, and Spellman \& Bjork, 1992, for alternative explanations). Thus, we elicited JOL ratings at one of two times for the 30 paired associates in this study: (1) immediately after study (hereafter referred to as JOL-I), or (2) after all the pairs had been studied-a delay of about $4 \mathrm{~min}$ (hereafter referred to as JOL-D). Paired associates were randomly assigned to each condition for each participant, with the restriction that 15 pairs received immediate JOLs and 15 received delayed JOLs.

Feeling of knowing. Twenty-five general knowledge questions were obtained from Nelson and Narens's (1980) norms (e.g., What is the name of the organ that produces insulin?). Participants answered the 25 questions one at a time, at their own pace. In order to minimize errors due to misspellings, the computer scored a response as correct if the first three letters matched those of the correct response. Feedback for the accuracy of each response was not provided. After participants had answered all 25 questions, the questions were again shown. For each question, participants selected a rating that best reflected their likelihood of recognizing the correct answer on a four-alternative multiple choice test. Participants chose one of six ratings: $25 \%$ confident (chance performance), $40 \%, 55 \%, 70 \%, 85 \%$, and $100 \%$ (definitely would recognize). After all questions received an FOK rating, a four-alternative multiple choice test was administered over the 25 questions. The order of question presentation was randomized for each of the three phases (i.e., recall test, FOK judgment, and recognition test). This procedure was based on that used by Koriat $(1993,1995)$ and was slightly different from other FOK studies. Often, researchers elicit FOK judgments only for incorrect items. In our experiment, participants rated all 25 items and were not informed which items they answered incorrectly on the initial test (for further discussion, see Krinsky \& Nelson, 1985). For comparison, we used the more standard FOK procedure in Experiment 2.

Text comprehension. Participants read four narrative texts, ranging from 210 to 343 words. All narratives were derived from the materials used by Weaver and Bryant (1995). Readability was assessed using the Flesch reading ease scale, with grade level ranging from 8 to 12 (mean grade level $=9.8$ ). Immediately after reading a text passage, participants made a judgment as to how well they would perform on a four-alternative multiple choice test over the material. Participants chose one of six ratings: $25 \%$ (chance performance), $40 \%, 55 \%, 70 \%, 85 \%$, or $100 \%$ of the items would be answered correctly. The order of text presentation was randomized for each participant. After reading and rating each passage, participants completed a four-alternative forced-choice math test for $5 \mathrm{~min}$. Feed- back was again provided, and participants were instructed to be as accurate as possible. After participants completed this distractor task, a 10-item four-alternative test was presented for each text passage. Question order was randomized, but all 10 questions over a given text were always presented together.

Design. Participants were tested in groups that ranged in size from one to six. A $4 \times 4$ Latin square was randomly generated as described by Kirk (1995, pp. 322-323). Participants were assigned to rows, and task presentation was determined by column order for each row. Once task order was determined, condition version (A or B) was determined independently by a coin toss. Two versions of each task were generated. These versions were procedurally identical; the only difference was in experimental stimuli. For example, the four texts used in Version A were unrelated to those used in Version B. The two versions of each task were constructed so that they would have a similar range of difficulty by using existing norms. We also matched the range of difficulty across the four tasks as closely as possible.

Participants received verbal instructions for all four tasks before beginning the experiment. Additional instructions were presented on the computer before each condition began. Participants were allowed to take breaks between the four conditions, but once they began a task, they were not allowed to pause. Completion of the entire experiment required about 100-120 min. Participants returned 1 week later at the same time. A second Latin square was generated for this session, and condition order was assigned as described above. Participants were tested on the same computer as before and completed the alternate version of each task.

\section{Results}

Descriptive statistics for memory accuracy (i.e., recall and recognition test performance), confidence, and metacognitive accuracy appear in Table $1 .{ }^{4} \mathrm{~A}$ within-subjects analysis of variance (MANOVA) was used to analyze differences between test sessions. Unless otherwise specified, alpha was set at .05 for all tests of statistical reliability.

\section{Table 1}

Descriptive Statistics for All Dependent Measures in Sessions 1 and 2 of Experiment 1

\begin{tabular}{lccccc}
\hline & \multicolumn{2}{c}{ Session 1} & & \multicolumn{2}{c}{ Session 2} \\
\cline { 2 - 3 } \cline { 5 - 6 } Measure and Condition & $M$ & $S E M$ & & $M$ & $S E M$ \\
\hline Memory accuracy & & & & \\
EOL & .71 & .03 & .74 & .03 \\
JOL-immediate & .44 & .03 & .50 & .03 \\
JOL-delayed & .54 & .03 & .56 & .03 \\
FOK & .65 & .02 & .65 & .02 \\
TCM & .72 & .02 & .71 & .02 \\
Predicted accuracy & & & & \\
EOL & .49 & .02 & .52 & .02 \\
JOL-immediate & .49 & .02 & .48 & .02 \\
JOL-delayed & .52 & .03 & .52 & .03 \\
FOK & .60 & .02 & .60 & .02 \\
TCM & .73 & .02 & .69 & .02 \\
Metamemory accuracy $(G)$ & & & & \\
EOL & .39 & .06 & .13 & .08 \\
JOL-immediate & .43 & .06 & .42 & .06 \\
JOL-delayed & .79 & .05 & .78 & .04 \\
FOK & N/A & & N/A & \\
TCM & .44 & .09 & .38 & .10 \\
\hline NCM & &
\end{tabular}

Note- The memory accuracy scores in the EOL task are the mean proportion of items correct on the first test trial; $G$ correlations were computed between predicted and actual performance. N/A, cell entry could not be computed (see text for details). EOL, ease of learning; JOL. judgment of learning; FOK, feeling of knowing; TCM, text comprehension monitoring. 
Memory. The mean proportion correct on memory tests was computed for all four tasks. Because multiple tests were used in the EOL condition, the proportion of items correct on the first test is shown at the top of Table 1. Intermediate levels of recall and recognition were observed in all conditions. No reliable differences were detected between sessions in any of the four tasks.

Confidence. Participants' overall confidence levels generally were consistent between sessions (see "Predicted Accuracy" in Table 1). The TCM condition showed a small but statistically reliable decline in predicted performance over the 1 -week interval [mean difference $=$ $.04, F(1,61)=6.53$ ]. No reliable differences were observed between sessions in any other task.

Metacognitive accuracy. Metacognitive performance can be assessed in a number of ways. We used $G$ correlations as the primary measure of relative metacognitive accuracy (for rationale, see Nelson, 1984, 1996b; Wright, 1996; see note 1 for a description of $G$ ). Alternative indices of metacognition-which provide different types of information - are commonly used by researchers in related areas (e.g., education, decision making). Maki (1998) has recommended that investigators use multiple measures of metacognition. For completeness, we also computed measures of bias and discrimination (listed in Appendices A-C) in addition to $G$.

The bias index reflects participants' overall overconfidence or underconfidence in a given task (Yates, 1990). Bias scores were derived by obtaining the signed difference between mean confidence and mean performance for each participant. A bias score greater than 0 indicates general overconfidence, and a bias score less than 0 indicates general underconfidence.

Discrimination scores are defined as the difference in confidence for items correctly recalled minus confidence for items that are not recalled (Lundeberg, Fox, \& Puncochar, 1994; Schraw et al., 1995). A discrimination score greater than zero indicates relatively high metacognitive performance-confidence is high for correct responses, but low for incorrect responses. A discrimi- nation score less than 0 indicates relatively low discrimination-confidence is low for correct responses, but high for incorrect responses. Some discrimination scores could not be computed in Experiment 1 (these are marked "N/A" in Appendices A and B). In the TCM condition, for example, we followed a protocol (Weaver \& Bryant, 1995 ) in which one confidence rating was correlated with performance on 10 memory questions, but computational procedures for discrimination scores require one confidence rating for each content question.

Summary statistics for $G$ are listed at the bottom of Table 1. Mean values were analyzed using one-sample $t$ tests, and all Gs were reliably nonzero, except in Session 2 of the EOL task (mean $G=.13$ ). A statistically reliable difference was observed between sessions in the EOL condition $[F(1,50)=5.05]$. In the FOK condition, specific confidence ratings could not be matched with accuracy for those items because of a computer coding error, so mean $G$ s (and discrimination scores) were not available.

Consistent with Nelson and Dunlosky (1991), we obtained a robust delayed-JOL effect. Metacognitive performance in the JOL condition was better after a short delay $(G=.79$ in Session 1 and $G=.78$ in Session 2$)$ than immediately after study $[G=.43$ in Session 1 and $G=.42$ in Session 2; $F(1,56)=25.0$ for Session 1 , and $F(1,53)=$ 27.7 for Session 2]. Thus, metacognitive accuracy was reliably nonzero in all tasks, and the magnitude of effects was similar to those obtained in past research (see Kelemen \& Weaver, 1997; Nelson \& Dunlosky, 1991).

Correlations between different metacognitive tasks. We examined whether memory, confidence, and metacognitive accuracy were consistent across the four tasks. For example, would a confident (or accurate) participant in the EOL task also be confident (or accurate) in the JOL task? Component measures of metacognitive accuracy (i.e., memory and confidence) themselves were generally consistent between tasks, but metacognitive accuracy (the correlation between confidence and memory) itself was inconsistent. We calculated Spearman $r$ correlations to assess the consistency between tasks for both

Table 2

Spearman $r$ Correlations Between Measures of Memory Accuracy (Below the Main Diagonal) and Confidence (Above the Main Diagonal) in Experiment 1

\begin{tabular}{lcccccccccc}
\hline & EOL1 & EOL2 & JOL-I1 & JOL-I2 & JOL-D1 & JOL-D2 & FOK1 & FOK2 & TCM1 & TCM2 \\
\hline EOL1 & 1.0 & $.38 \dagger$ & $.42 \dagger$ & $.41 \dagger$ & $.53 \dagger$ & $.38 \dagger$ & .24 & .14 & .21 & $.35 \dagger$ \\
EOL2 & $.52 \dagger$ & 1.0 & $.38 \dagger$ & $.70 \dagger$ & $.40 \dagger$ & $.47 \dagger$ & .09 & .08 & $.28^{*}$ & $.39 \dagger$ \\
JOL-I1 & $.35 \dagger$ & $.33 \dagger$ & 1.0 & $.61 \dagger$ & $.58 \dagger$ & $.46 \dagger$ & .22 & .21 & .19 & $.35 \dagger$ \\
JOL-12 & $.34 \dagger$ & $.35 \dagger$ & $.62 \dagger$ & 1.0 & $.52 \dagger$ & $.64 \dagger$ & $.28^{*}$ & .23 & $.36 \dagger$ & $.37 \dagger$ \\
JOL-D1 & $.45^{*}$ & $.41 \dagger$ & $.70 \dagger$ & $.59 \dagger$ & 1.0 & $.56 \dagger$ & -.01 & .02 & .10 & .16 \\
JOL-D2 & $.32^{*}$ & $.55 \dagger$ & $.53 \dagger$ & $.68 \dagger$ & $.50 \dagger$ & 1.0 & $.35 \dagger$ & .15 & $.31^{*}$ & $.31^{*}$ \\
FOK1 & $.30^{*}$ & .04 & -.10 & .04 & .01 & -.02 & 1.0 & $.68 \dagger$ & $.52 \dagger$ & $.45 \dagger$ \\
FOK2 & $.44 \dagger$ & $.27^{*}$ & .02 & .07 & .06 & -.03 & $.61 \dagger$ & 1.0 & $.51 \dagger$ & $.44 \dagger$ \\
TCM1 & $.33 \dagger$ & $.29^{*}$ & .24 & $.32^{*}$ & $.30^{*}$ & .14 & $.28^{*}$ & $.35 \dagger$ & 1.0 & $.69 \dagger$ \\
TCM2 & $.35^{*}$ & $.39 \dagger$ & .21 & .26 & $.29^{*}$ & .25 & .18 & $.30^{*}$ & $\mathbf{. 6 3} \dagger$ & 1.0 \\
\hline
\end{tabular}

Note-Correlations between confidence measures are above the main diagonal; memory accuracy correlations appear below the main diagonal. Correlations between sessions, but within a particular metacognitive task condition, are shown in boldface for ease of comparison. EOL, ease of learning; JOL, judgment of learning; FOK, feeling of knowing; TCM, text comprehension monitoring. ${ }^{*} p<.05 ;{ }^{\dagger} p<.01$. 
Table 3

Spearman $\boldsymbol{r}$ Correlations Between $\boldsymbol{G}$ Scores in Experiment 1

\begin{tabular}{lcccccccr}
\hline & EOL1 & EOL2 & JOL-11 & JOL-12 & JOL-D1 & JOL-D2 & TCM1 & TCM2 \\
\hline EOL1 & 1.0 & .13 & -.15 & .14 & -.15 & .05 & .04 & .03 \\
EOL2 & & 1.0 & .10 & -.20 & .10 & -.23 & .00 & .00 \\
JOL-11 & & & 1.0 & .01 & $.34 \dagger$ & .14 & $.31^{*}$ & .08 \\
JOL-12 & & & & 1.0 & -.01 & .01 & .28 & -.04 \\
JOL-D1 & & & & & 1.0 & .08 & .26 & .10 \\
JOL-D2 & & & & & & 1.0 & .05 & -.04 \\
TCM1 & & & & & & & 1.0 & .06 \\
TCM2 & & & & & & & & 1.0 \\
\hline
\end{tabular}

Note-Correlations between sessions, but within a particular metacognitive task condition, are shown in boldface for ease of comparison. EOL, ease of learning; JOL, judgment of learning; TCM, text comprehension monitoring. ${ }^{*} p<.05 ;{ }^{\dagger} p<.01$.

memory and confidence (Table 2). Correlations of memory scores are shown below the main diagonal, and confidence scores are shown above it. Component measures were significantly correlated between tasks in 51 out of 80 cases (about $64 \%$ of the time) shown in Table 2 . In contrast, few $(2 / 24$, about $8 \%)$ of the $G$ s were consistent between tasks (Table 3 ).

Test-retest reliability. We also examined whether memory, confidence, and metacognitive accuracy were consistent within a given task over the 1-week interval.
For example, would a participant with high performance in the EOL task on Day 1 also perform well in the EOL task 1 week later? Component measures showed significant test-retest reliability in all four tasks: Both memory and confidence scores were always stable between sessions ( $10 / 10$; see entries in boldface in Table 2$)$. In contrast, none of the test-retest correlations were reliably nonzero for $G$ (see entries in boldface in Table 3). This relationship is summarized graphically in Figure 1. Clearly, the mean test-retest reliabilities for memory and
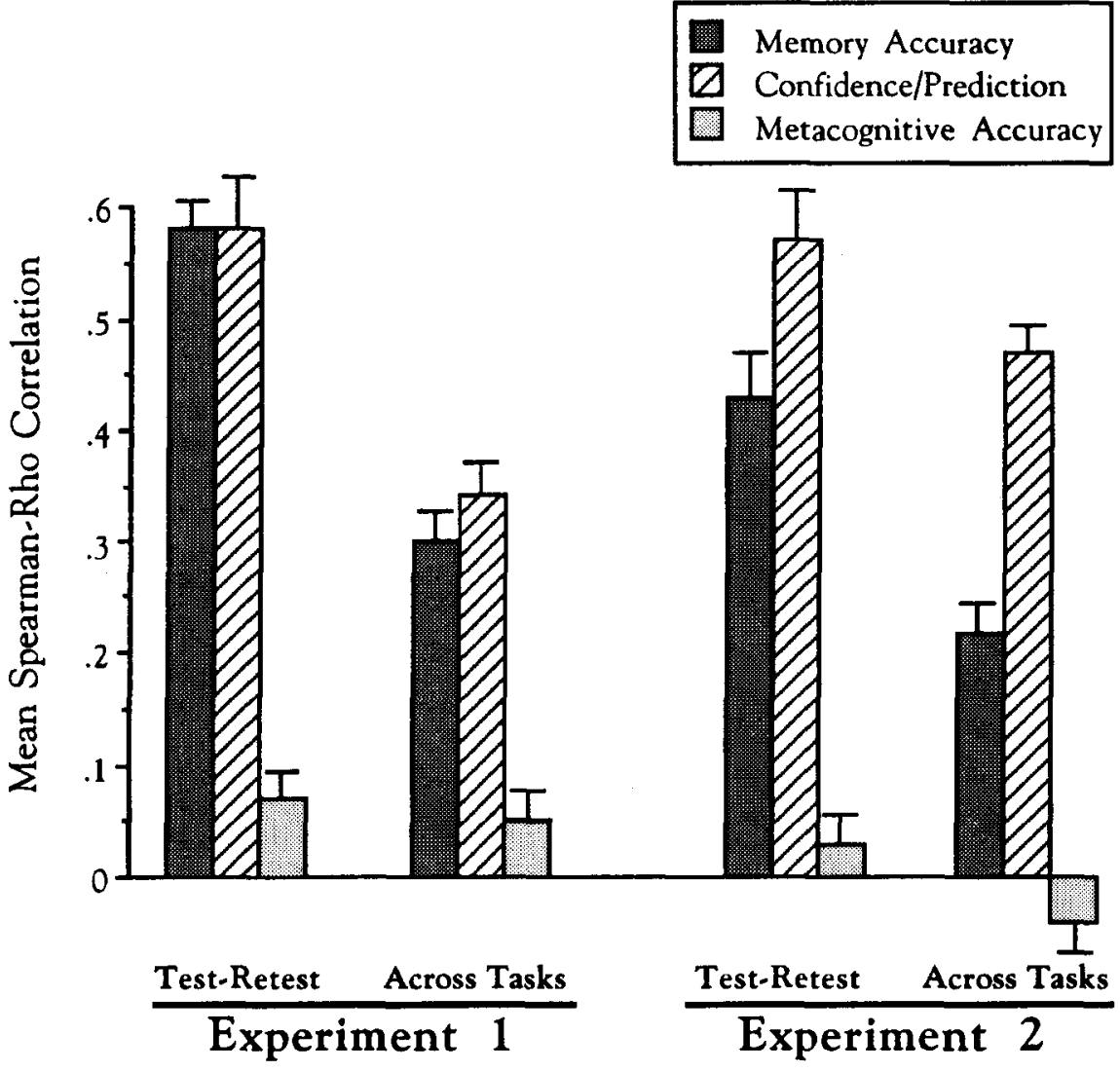

Figure 1. Mean test-retest and across-task reliability (with standard errors) for memory performance, confidence/predictions, and metacognitive accuracy in Experiments 1 and 2. 
confidence scores were quite high relative to the mean test-retest reliability for $G$.

\section{Discussion}

Participants showed typical, modest metacognitive accuracy in EOL, JOL, and TCM tasks. Mean Gs in these tasks were consistent with those observed in past research (see, e.g., Leonesio \& Nelson, 1990, for comparisons values of EOL and JOL; see Weaver \& Bryant, 1995, for a comparison with TCM values). In addition, JOL accuracy after short delays was reliably better than JOLs made immediately after study--the delayed-JOL effect (Nelson \& Dunlosky, 1991). Thus, we feel confident that our results are representative of those obtained in past studies of metacognition.

The most striking finding of Experiment $l$ is the near complete lack of reliability in metacognitive accuracy relative to memory and confidence (Figure 1). Individual differences in memory and confidence were consistent (Table 2), as was the signed difference between these measures (see bias scores in Appendix B). However, the data in Table 3 indicate that individual differences in metacognitive accuracy were not reliable.

One might wonder if the lack of reliability in metacognitive accuracy was an artifact of computing correlations between ranked correlations $(G \mathrm{~s})$. This alternative is untenable for two reasons. First, $G$ s can easily be converted into probability statements using the formula shown in note 1, which are suitable for comparison (or, in this case, correlation) by any standard. Second, we replicated this unreliability using discrimination scores as an index of metacognitive accuracy. The discrimination scores in Appendix B display the same inconsistency as that observed with $G$, suggesting that unreliability does not exist in $G$ per se, but rather in the underlying data structure.

\section{EXPERIMENT 2}

The same basic procedures were used in Experiment 2, but we made modifications so that the assessment of metacognitive accuracy was identical in each condition. The tasks in Experiment 1 were constructed to resemble typical studies in each domain. However, this resulted in a different number of items being used to compute $G$ for each condition. Twenty-five questions were used for FOK, and 15 items were used for EOL, JOL-I, and JOL-D, but participants made only four judgments in the TCM task. Moreover, one prediction was correlated with one item in the FOK, JOL, and EOL conditions, but each prediction was correlated with the proportion correct on 10 test questions in the TCM condition. Perhaps this variability in memory and metamemory measurement produced unreliable results.

In Experiment 2, the same number of judgments and test questions (15) was used in each task. We modified the TCM condition so that participants read 15 short texts, made a prediction for each, and then received one test question for each text. This is similar to the procedures followed by Glenberg and his colleagues (e.g., Glenberg et al., 1987), who observed very poor monitoring of comprehension. Although TCM performance is higher if several questions are used to assess comprehension (Weaver, 1990), we adopted the Glenberg methodology to keep test procedures identical across metacognitive tasks (i.e., each judgment matched with one memory test question). The FOK condition was modified so that participants made judgments only on the first 15 items they answered incorrectly. In addition, participants were informed that they initially answered these questions incorrectly. Because $G$ after a delay was no more stable than $G$ after no delay in Experiment 1, delayed judgments were excluded from the JOL condition. Participants made 15 JOLs immediately after study. Finally, difficulty level of the 15 pairs in the EOL task was increased to make mean memory performance more consistent with the other conditions.

\section{Method}

Participants. Seventy-eight Baylor undergraduates volunteered for Experiment 2 and received course credit. None of these participants had volunteered for Experiment 1.

Ease of learning. Fifteen Swahili-English paired associates were again drawn from Nelson and Dunlosky (1994). The five easiest items were dropped from Experiment 1 and replaced with more normatively difficult pairs. Study time for each pair was reduced to $5 \mathrm{sec}$. Both changes were designed to increase task difficulty and variability in the trials-to-learn criterion. All other procedures were identical to those of Experiment 1.

Judgment of fearning. A subset of 15 noun pairs was drawn from Experiment 1 . Because this represents only half the total number of items learned previously, study time for each pair was reduced to 4 sec to avoid ceiling performance. All JOLs were made immediately after study and were prompted by the cue word alone.

Feeling of knowing. Thirty-five general knowledge questions were drawn from Nelson and Narens (1980). Participants answered all 35 questions, but they made FOK ratings only for the first 15 questions that they answered incorrectly. Participants were informed that they had previously answered these questions incorrectly before making FOKs. A four-alternative recognition test on all 35 items was administered.

Text comprehension. Fifteen distinct narrative paragraphs were adapted for use from Angus (1985) and Bain, Beaty, and Hunter (1986). Paragraph length ranged from 84 to 118 words. Readability ranged from a grade level of 9 to 13 (mean grade level $=12.3$ ). Immediately after reading each paragraph, participants made a confidence rating regarding future test performance. Following a 5-min math problem distractor, participants answered one four-alternative recognition question over each paragraph. Paragraph order and test question order were randomized for each participant.

Design. New Latin squares were generated (see Kirk, 1995, pp. 322-323) and used to assign condition order to participants. All other experimental protocols were identical to those in Experiment 1.

\section{Results}

Memory. The mean proportions correct on all four memory tests are listed in Table 4. Intermediate levels of recall and recognition were again noted. MANOVA revealed no reliable differences between sessions. 
Table 4

Descriptive Statistics For All Dependent Measures in Sessions 1 and 2 of Experiment 2

\begin{tabular}{llllll}
\hline & \multicolumn{2}{c}{ Session 1} & & \multicolumn{2}{c}{ Session 2 } \\
\cline { 5 - 6 } \cline { 5 - 6 } Measure and Condition & $M$ & $S E M$ & & $M$ & $S E M$ \\
\hline Memory accuracy & & & & \\
$\quad$ EOL & .65 & .03 & .58 & .03 \\
JOL & .42 & .03 & .41 & .03 \\
FOK & .54 & .02 & .54 & .02 \\
TCM & .75 & .02 & .73 & .02 \\
Predicted accuracy & & & & \\
EOL & .48 & .02 & .46 & .02 \\
JOL & .53 & .02 & .49 & .02 \\
FOK & .51 & .01 & .52 & .01 \\
TCM & .65 & .02 & .62 & .02 \\
Metacognitive accuracy $(G)$ & & & & \\
EOL & .30 & .06 & .35 & .05 \\
JOL & .44 & .05 & .49 & .04 \\
FOK & .33 & .05 & .29 & .04 \\
TCM & .02 & .06 & .05 & .06
\end{tabular}

Note-The memory accuracy scores in the EOL task are the mean proportion of items correct on the first test trial; $G$ correlations were computed between predicted and actual performance. EOL, ease of learning; JOL, judgment of learning; FOK, feeling of knowing; TCM, text comprehension monitoring.

Confidence. Participants' overall confidence levels generally were consistent between sessions (Table 4). A small but statistically reliable decrease was found for predicted performance in the JOL condition $[F(1,67)=$ 6.81 ]. No reliable differences were observed between sessions in any other task.

Metacognitive accuracy. Mean $G$ s are listed in Table 4. One-sample $t$ tests revealed values that were all reliably nonzero except in the TCM condition. A MANOVA revealed no reliable differences in $G$ between sessions.

Correlations between different metacognitive tasks. We examined the reliability of memory, confidence, and metacognitive accuracy between tasks. As in Experiment 1 , both memory and confidence were usually consistent between tasks, but metacognitive accuracy was inconsistent. Memory and confidence scores were sig- nificantly correlated between tasks in 32 out of 48 cases (about 67\%; see Table 5). In contrast, only 3 of the 24 correlations $(12 \%)$ of $G$ s across tasks were nonzero, and two of these were not in the expected direction (Table 6).

Test-retest reliability. We also examined test-retest stability over the 1-week interval within each task. Both memory and confidence scores showed reliable test-retest correlations in all four tasks $(8 / 8$; see entries in boldface in Table 5). Examination of metacognitive accuracy values showed the opposite pattern: None of the test-retest correlations of $G$ were reliably nonzero $(0 / 4$; see entries in boldface in Table 6).

To facilitate comparisons between memory accuracy, confidence/predicted performance, and metamemory accuracy, Figure 1 displays the data in Tables 2, 3, 5, and 6 graphically. Individual differences in memory performance were stable, with both test-retest and across-task procedures, in both Experiments 1 and 2. The same was true for individual differences in confidence ratings and predictions of performance. Differences in metamemory accuracy, however, were not stable.

\section{Discussion}

Experiment 2 replicated the main findings of Experiment 1 , despite procedural changes in each of the four metacognitive tasks. Modest, typical metacognitive accuracy was observed in the EOL, JOL, and FOK conditions. Memory scores and overall confidence were reliable (Table 5), and bias scores again reflected this stability (Appendix C). However, $G$ showed a nearly complete lack of reliability. Appendix $\mathrm{C}$ also confirms this pattern: No reliability was noted in discrimination scores. Experiment 2 suggests that these findings were not due to differences in the number of items used to compute metacognitive accuracy, because each of the four tasks elicited 15 predictions-one for each test question.

This methodological change may have produced the low $G$ s (and discrimination scores) in the TCM condition. Several studies have revealed very poor metacognition for texts when comprehension is assessed with only

Table 5

Spearman $r$ Correlations Between Measures of Memory Accuracy (Below the Main Diagonal) and Confidence (Above the Main Diagonal) in Experiment 2

\begin{tabular}{lcccccccc}
\hline & EOL1 & EOL2 & JOL1 & JOL2 & FOK1 & FOK2 & TCM1 & TCM2 \\
\hline EOL1 & 1.0 & $.52 \dagger$ & $.46 \dagger$ & $.56 \dagger$ & $.38 \dagger$ & $.38 \dagger$ & $.49 \dagger$ & $.40 \dagger$ \\
EOL2 & $.51 \dagger$ & 1.0 & $.56 \dagger$ & $.67 \dagger$ & $.41 \dagger$ & $.64 \dagger$ & $.52 \dagger$ & $.50 \dagger$ \\
JOL1 & $.38 \dagger$ & $.33 \dagger$ & 1.0 & $.69 \dagger$ & $.34 \dagger$ & $.33 \dagger$ & $.59 \dagger$ & $.54 \dagger$ \\
JOL2 & $.39 \dagger$ & $.46 \dagger$ & $.52 \dagger$ & 1.0 & $.33 \dagger$ & $.51 \dagger$ & $.43 \dagger$ & $.49 \dagger$ \\
FOK1 & .19 & -.03 & .18 & .09 & 1.0 & $.47 \dagger$ & $.45 \dagger$ & $.40 \dagger$ \\
FOK2 & .15 & .15 & .17 & .16 & $.32 \dagger$ & 1.0 & $.36 \dagger$ & $.47 \dagger$ \\
TCM1 & .17 & .12 & $.28^{*}$ & .22 & .17 & .07 & 1.0 & $.59 \dagger$ \\
TCM2 & .20 & $.27^{*}$ & $.25^{*}$ & $.28^{*}$ & .13 & .18 & $.37 \dagger$ & 1.0 \\
\hline
\end{tabular}

Note--Correlations between confidence measures are above the main diagonal; memory accuracy correlations appear below the main diagonal. Correlations between sessions, but within a particular metacognitive task condition, are shown in boldface for ease of comparison. EOL, ease of learning; JOL, judgment of learning; FOK, feeling of knowing; TCM, text comprehension monitoring. ${ }^{*} p<.05 ; \quad{ }^{\dagger} p<.01$. 
Table 6

Spearman $\boldsymbol{r}$ Correlations Between $\boldsymbol{G}$ Scores in Experiment 2

\begin{tabular}{lcccrrrrr}
\multicolumn{7}{c}{ Spearman $\boldsymbol{r}$ Correlations Between } \\
& EOL1 & EOL2 & JOL1 & JOL2 & FOK1 & FOK2 & TCM1 & TCM2 \\
\hline EOL1 & 1.0 & -.07 & -.18 & .05 & .10 & .04 & $.24^{*}$ & -.07 \\
EOL2 & & 1.0 & -.03 & -.20 & -.15 & .11 & .05 & .10 \\
JOL1 & & & 1.0 & .07 & -.07 & -.08 & -.20 & -.08 \\
JOL2 & & & & 1.0 & $-.32 \dagger$ & -.11 & .08 & -.07 \\
FOK1 & & & & & 1.0 & -.02 & -.05 & $-.24^{*}$ \\
FOK2 & & & & & & 1.0 & .07 & .04 \\
TCM1 & & & & & & & 1.0 & -.01 \\
TCM2 & & & & & & & & 1.0 \\
\hline
\end{tabular}

Note-Correlations between sessions, but within a particular metacognitive task condition, are shown in boldface for ease of comparison. EOL, ease of learning; JOL, judgment of learning; FOK, feeling of knowing; TCM, text comprehension monitoring. $\quad{ }^{*} p<.05 ; \quad{ }^{\dagger} p<.01$.

one question (e.g., Glenberg \& Epstein, 1985, 1987; Glenberg et al., 1987). Weaver (1990) determined that $G$ increases substantially as more test questions are included for each text, independent of changes in calibration. Modest monitoring accuracy for texts was observed when 10 memory questions were used per text in Experiment 1 (mean $G=.41$ ); a complete lack of monitoring proficiency was observed in Experiment 2 when only one memory question was used per text. Together, these results conceptually replicated Weaver's findings. It was necessary, however, to generate additional texts for Experiment 2 . An alternative possibility is that some idiosyncratic properties of the new texts lowered metacognitive accuracy. In either case, individual differences in TCM were completely unreliable in both experiments.

\section{GENERAL DISCUSSION}

We conducted two experiments to examine the reliability of individual differences in metacognitive accuracy. Participants showed reasonable levels of metacognition in EOL, JOL (both immediate and delayed), FOK, and TCM paradigms. Component measures of metacognitive accuracy (i.e., memory and confidence) were correlated across these tasks over $60 \%$ of the time in both experiments. In contrast, metacognitive accuracy itself $(G)$ correlated across tasks only $8 \%$ of the time in Experiment 1, and 12\% of the time in Experiment 2. Test- retest correlations showed an even greater difference. Component measures showed reliable test-retest correlations for every task in Experiments 1 and 2. Conversely, test-retest correlations of metacognitive accuracy were never reliably nonzero!

The pattern of our results is clear, striking, and consistent. Memory and confidence levels were stable, but metacognitive accuracy was not. Moreover, the bias scores in Appendices $B$ and $C$ indicated that individual differences in overconfidence and underconfidence also were reliable. This replicates the findings of Schraw et al. (1995): Overconfident (or underconfident) participants tended to remain so over time and across tasks. This also demonstrates that we did detect reliable individual differences where they existed. In contrast, analyses of $G$ and discrimination scores failed to show any reliable individual differences in metacognitive accuracy.

\section{Unreliability of Metacognitive Accuracy}

The present findings are consistent with past observations of unreliability in metacognitive performance. We replicated Leonesio and Nelson's (1990) finding that metacognitive accuracy in different types of judgments is weakly (and usually nonreliably) correlated. We also replicated Thompson and Mason's (1996) finding that metacognitive performance is not stable over time, even in the same predictive task. The pattern of results is unambiguous, but might these data represent procedural artifacts rather than genuine differences?

As outlined above, numerous methodological factors can produce unreliability in metacognitive performance. One possibility is that we did not include enough items in our procedures to detect stable metacognitive performance. Although we held the number of items constant for each task in Experiment 2, the possibility remains that 15 items simply are not enough to detect genuine metacognitive ability. Nelson (1988) examined this very possibility, and he found that increasing the test length (i.e., from 30 to 110 questions) did not increase the split-half reliability of FOK judgments. Perhaps even 110 items is not enough. John Swets has proposed that this situation may be analogous to investigations in perceptual psychophysics, where many hundreds of trials are required to obtain stable measurements (personal communication, cited in Nelson, 1988). In the present study, administering hundreds of trials in each task would make our testing procedures unreasonably cumbersome. Thus, we cannot exclude the possibility that stable metacognitive performance might be detected using a very large number of trials. This remains an interesting hypothesis.

The observed lack of reliability over time was not due to a difference in the range of item difficulty within a task. Test materials in each condition were matched for difficulty between sessions based on existing norms. For ex- 
ample, a wide range of questions were selected for the FOK task (from Nelson \& Narens, 1980) and were split into groups of odd- and even-numbered items. This ensured that both the mean level of difficulty (shown in Tables 1 and 4) and the range of difficulty were consistent between sessions.

Correct guessing in recognition tests can obscure accurate memory monitoring performance by adding noise to observed memory performance. This might have contributed to the instability of metacognitive performance obtained in past research (e.g., Thompson \& Mason, 1996). Our Experiment 2 used two recognition tests of memory (TCM and FOK) and two recall tests (EOL and JOL). However, the mean test-retest correlations of $G s$ and discrimination scores shown in Table 6 were nearly identical for both types of tests; recognition tests $=.04$ and recall tests $=.05$. Thus, it does not appear that the type of memory test contributed substantially to the unreliability in metacognitive accuracy.

Inadequate assessment of memory (or confidence) can also add noise to $G$ s and produce instability in metacognitive accuracy. In Experiment 1, memory accuracy in TCM was assessed with 10 questions over each text (following the protocol of Weaver and Bryant, 1995), as opposed to only one question per item for the other tasks. The former procedure presumably produced a better memory index than the latter. Yet the test-retest correlations for $G$ in TCM $(.06)$ was not greater than that observed for EOLs (.13) and delayed JOLs (.08; see Table 3 ). In addition, the correlation of memory performance between sessions was nearly identical in the TCM (.63), immediate JOL (.62), and FOK (.61) conditions. Thus, it does not appear that inadequate memory assessment produced instability in our results. Finally, we included discrimination scores in addition to the standard correlational measure $G$ (see Appendices A-C). Instability emerged when both measures were used, suggesting that previous null findings (e.g., Nelson, 1988; Thompson \& Mason, 1996 ) were not due to reliance on $G$ exclusively as a measure of metacognitive accuracy.

\section{Individual Differences in Metacognitive Ability}

Differences in metacognitive accuracy are routinely demonstrated between groups as a function of task demands and altered physiological states, but stable individual differences in metacognition remain difficult to detect. One might expect metacognitive ability to be strongly related to memory ability. Most studies, however, have also failed to demonstrate this relationship, despite substantial variations in procedures and metacognitive domains (e.g., Cull \& Zechmeister, 1994; Kearney \& Zechmeister, 1989; Lovelace, 1984; Pressley \& Ghatala, 1990; Underwood, 1966). Lovelace proposed that this relationship can be demonstrated using a broad developmental framework. It is well known that both memory performance and metacognitive performance are worse for young children than for adults (e.g., Pressley, Levin, \& Ghatala, 1984; Wellman, 1978; Yussen \& Levy, 1975).
Several theoretical accounts of memory and metacognitive development have been proposed (e.g., Campbell \& Bickhard, 1986; Karmiloff-Smith, 1992). One interesting idea is that specific, idiosyncratic metacognitive skills become generalized late in development, and only after considerable effort (Schraw et al., 1995). Such ideas cannot be fully tested, however, until procedures that produce reliable measurements of metacognitive accuracy in adults have been developed.

Despite the present lack of evidence, the notion of stable individual differences in a general monitoring skill remains attractive. Our purpose here is to call attention to the need for strong empirical support for this assumption. We recognize that our study is correlational in nature and that it represents an early step in the search for stable individual differences. Clearly, evidence for a general monitoring skill will not be easy to obtain. For example, metacognitive ability might be multidimensional, with different types of metacognitive judgments tapping distinct components or combinations of components (Leonesio \& Nelson, 1990). Given that there is currently no test-retest reliability within any given task, however, the lack of evidence for a more general metacognitive ability is not surprising. We hope that our efforts will encourage others to join in the search for procedures that produce reliable measures of metacognitive accuracy.

The unreliability of metacognitive accuracy is particularly troubling given the progress that has been made in describing metacognition in general. Individuals do monitor their memory in a variety of situations, and their performance is based at least in part on internal, privileged - and presumably, stable - access to their memory processes (Nelson, Leonesio, et al., 1986). We believe that our tasks were representative of those used in EOL, JOL, FOK, and TCM domains. Thus, our null effects represent a broad concern to investigators in a variety of metacognitive paradigms. The finding that there may be deficiencies in testing procedures (e.g., not including enough items in each test) has important implications for the field, because these procedures are used widely. Important work in metacognition can continue given current techniques, but a full understanding of the phenomenon will not emerge until the puzzle concerning individual differences in metacognition is solved.

\section{REFERENCES}

ANGUS, D. (ED.) (1985). The best short stories of the modern age (rev. ed.). New York: Fawcett Premier.

ARBUCKLE, T. Y., \& CUDDY, L. L. (1969). Discrimination of item strength at time of presentation. Joumal of Experimental Psychology, 81, 126-131.

Bain, C. E., Beaty, J., \& Hunter, J. P. (1986). The Norton introduction to literature (4th ed.). New York: Norton.

Begg, I., Duft, S., Lalonde, P., Melnick, R., \& Sanvito, J. (1989). Memory predictions are based on ease of processing. Journal of Memory \& Language, 28, 610-632.

CAMPBell, R. L., \& BICKhaRD, M. H. (1986). Knowing levels and developmental stages. New York: Karger.

Costermans, J., Lories, G., \& Ansay, C. (1992). Confidence level and feeling of knowing in question answering: The weight of inferential 
processes. Journal of Experimental Psychology: Learning, Memory, \& Cognition, 18, 142-150.

Cull, W. L., \& Zechmeister, E. B. (1994). The learning ability paradox in adult metamemory research: Where are the metamemory differences between good and poor learners? Memory \& Cognition, 22, 249-257.

Dunlosky, J., \& Nelson, T. O. (1992). Importance of the kind of cue for judgments for learning (JOL) and the delayed-JOL effect. Memory \& Cognition, 20, 374-380.

Dunlosky, J., \& NELSON, T. O. (1994). Does the sensitivity of judgments of learning (JOLs) to the effects of various study activities depend on when the JOLs occur? Journal of Memory \& Language, 33, 545-565.

Dunlosky, J., \& SchwarTz, B. L. (1995, November). Does relational information affect people's predictions of eventual free recall? Poster session presented at the annual meeting of the Psychonomic Society, Los Angeles.

Gernsbacher, M. A., Varner, K. R., \& Faust, M. E. (1990). Investigating differences in general comprehension skill. Journal of Experimental Psychology: Learning, Memory, \& Cognition, 16, 430-445.

GlenderG, A. M., \& EPSTEIN, W. (1985). Calibration of comprehension. Journal of Experimental Psychology: Learning, Memory, \& Cognition, 11, 702-718.

GlenberG, A. M., \& EpSTeIN, W. (1987). Inexpert calibration of comprehension. Memory \& Cognition, 15, 84-93.

Glenberg, A. M., SANocki, T., Epstein, W., \& Morris, C. (1987). Enhancing calibration of comprehension. Journal of Experimental Psychology: General, 116, 119-136.

GlenberG, A. M., Wilkinson, A. C., \& Epstein, W. (1982). The illusion of knowing: Failure in the self-assessment of comprehension. Memory \& Cognition, 10, 597-602.

GLOVER, J. A. (1989). Improving readers' estimates of learning from text: The role of inserted questions. Reading Research Quarterly, 28, 68-75.

HART, J. T. (1965). Memory and the feeling-of-knowing experience. Journal of Educational Psychology, 56, 208-216.

Karmiloff-Smith, A. (1992). Beyond modularity: A developmental perspective on cognitive science. Cambridge, MA: MIT Press.

KeARNEY, E. M., \& ZeChMEISTER, E. B. (1989). Judgments of item difficulty by good and poor associative learners. American Journal of Psychology, 102, 365-383.

KFLEMEN, W. L., \& WEAVER, C. A., III (1997). Enhanced metamemory at delays: Why do judgments of learning improve over time? Journal of Experimental Psychology: Learning, Memory, \& Cognition, 23, 1394-1409.

King, J. F., Zechmeister, E. B., \& Shaughnessy, J. J. (1980). Judgments of knowing: The influence of retrieval practice. American Journal of Psychology, 93, 329-343.

KIRK, R. E. (1995). Experimental design: Procedures for the behavioral sciences (3rd ed.). Pacific Grove, CA: Brooks/Cole.

Koriat, A. (1993). How do we know what we know? The accessibility account of the feeling of knowing. Psychological Review, 100, 609-639.

KORIAT, A. (1994). Metamemory's knowledge of its own knowledge: The accessibility account of the feeling of knowing. In J. Metcalfe \& A. P. Shimamura (Eds.), Metacognition: Knowing about knowing (pp. 185-206). Cambridge, MA: MIT Press.

KoRIAT, A. (1995). Dissociating knowing and the feeling of knowing; Further evidence for the accessibility model. Journal of Experimental Psychology: General, 124, 311-333.

KORIAT, A. (1997, November). Practice improves resolution but impairs calibration: A cue-utilization approach to judgments of learning. Paper presented at the annual meeting of the Psychonomic Society, Philadelphia.

KRINSKy, R., \& Nelson, T. O. (1985). The feeling of knowing for different types of retrieval failure. Acta Psychologica, 58, 141-158.

LEONESIO, R. J., \& Nelson, T. O. (1990). Do different metamemory judgments tap the same underlying aspects of memory? Journal of Experimental Psychology: Learning, Memory, \& Cognition, 16, 464-470.

LOVELACE, E. A. (1984). Metamemory: Monitoring future recallability during study. Journal of Experimental Psychology: Learning, Memory, \& Cognition, 10, 756-766.
Lundeberg, M. A., Fox, P. W., \& Puncochar, J. (1994). Highly confident but wrong: Gender differences and similarities in confidence judgments. Journal of Educational Psychology, 86, 114-121.

MAKI, R. H. (1998). Metacomprehension of text: Influence of absolute confidence level on bias and accuracy. In D. L. Medin (Ed.), The psychology of learning and motivation (Vol. 38, pp. 223-248). San Diego: Academic Press.

MAKI, R. H., \& BERRY, S. L. (1984). Metacomprehension of text material. Journal of Experimental Psychology: Learning, Memory, \& Cognition, 10, 663-679.

Maki, R. H., Foley, J. M., Kajer, W. K., Thompson, R. C., \& Willert, M. G. (1990). Increased processing enhances calibration of comprehension. Journal of Experimental Psychology: Learning, Memory, \& Cognition, 16, 609-616.

MaKi, R. H., Jonas, D., \& Kallod, M. (1994). The relationship between comprehension and metacomprehension ability. Psychonomic Bulletin \& Review, 1, 126-129.

MaKI, R. H., \& SERRA, M. (1992). The basis of test predictions for text material. Journal of Experimental Psychology: Learning, Memory, \& Cognition, 18, 116-126.

MAKI, R. H., \& SwETT, S. (1987). Metamemory for narrative text. Memory \& Cognition, 15, 72-83.

Metcalfe, J., Schwartz, B. L., \& Joaquim, S. G. (1993). The cue familiarity heuristic in metacognition. Journal of Experimental Psychology: Learning, Memory, \& Cognition, 19, 851-861.

Metcalfe, J., \& Shimamura, A. P. (1994). Metacognition: Knowing about knowing. Cambridge, MA: MIT Press.

NELSON, T. O. (1984). A comparison of current measures of the accuracy of feeling-of-knowing predictions. Psychological Bulletin, 95 , 109-133.

Nelson, T. O. (1988). Predictive accuracy of the feeling of knowing across different criterion tasks and across different subject populations and individuals. In M. M. Gruenberg, P. E. Morris, \& R. N Sykes (Eds.), Practical aspects of memory: Current research and issues (Vol. 1, pp. 190-196). New York: Wiley.

Nelson, T. O. (1992). Metacognition: Core readings. Boston: Allyn \& Bacon.

Nelson, T. O. (1996a). Consciousness and metacognition. American Psychologist, 51, 102-116.

Nelson, T. O. (1996b). Gamma is a measure of the accuracy of predicting performance on one item relative to another item, not of the absolute performance of an individual item. Applied Cognitive Psychology, 10, 257-260.

Nelson, T. O., \& Dunlosky, J. (1991). When people's judgments of learning (JOLs) are extremely accurate at predicting subsequent recall: The "delayed-JOL effect." Psychological Science, 2, 267-270.

Nelson, T. O., \& Dunlosky, J. (1994). Norms of paired-associate recall during multitrial learning of Swahili-English translation equivalents. Memory, 2, 325-335.

Nelson, T. O., Dunlosky, J., White, D. M., Steinberg, J., Townes, B. D., \& ANDERSON, D. (1990). Cognition and metacognition at extreme altitudes on Mount Everest. Journal of Experimental Psychology: General, 119, 367-374.

Nelson, T. O., Leonesio, R. J., Landwehr, R. S., \& Narens, L. (1986). A comparison of three predictors of an individual's memory performance: The individual's feeling of knowing versus normative feeling of knowing versus base-rate item difficulty. Journal of Experimental Psychology: Learning, Memory, \& Cognition, 12, 279-287.

Nelson, T. O., Leonesio, R. J., Shimamura, A. P., Landwehr, R. S., \& NARENS, L. (1982). Overlearning and the feeling of knowing. Journal of Experimental Psychology: Learning, Memory, \& Cognition, 8 , 279-288.

Nelson, T. O., McSpadden, M., Fromme, K., \& Marlatt, G. A. (1986). Effects of alcohol intoxication on metamemory and on retrieval from long-term memory. Journal of Experimental Psychology: General, 115, 247-254.

NELSON, T. O., \& NARENS, L. (1980). Norms of 300 general-information questions: Accuracy of recall, latency of recall, and feeling-of-knowing ratings. Journal of Verbal Learning \& Verbal Behavior, 19, 338-368. 
Nelson, T. O., \& Narens, L. (1990). Metamemory: A theoretical framework and new findings. In G. H. Bower (Ed.), The psychology of learning and motivation (Vol. 26, pp. 125-173). San Diego: Academic Press.

Paivio, A., Yuille, J. C. \& Madigan, S. A. (1968). Concreteness, imagery, and meaningfulness values for 925 nouns. Journal of Experimental Psychology Monographs, 76 (1, Pt. 2).

Patton, J. H., Weaver, C. A., III, Burns, K. D., Brady, M. D., \& BRYANT, D. S. (1991, April). Cognitive impulsivity and cognitive skills. Paper presented at the annual meeting of the Southwestern Psychological Association, New Orleans.

Pressley, M., \& Ghatala, E. S. (1990). Self-regulated learning: Monitoring learning from text. Educational Psychologist, 25, 19-33

Pressley, M., Ghatala, E. S., Woloshyn, V., \& Pirie, J. (1990). Sometimes adults miss the main idea and do not realize it: Confidence in responses to short-answer and multiple-choice comprehension questions. Reading Research Quarterly, 25, 232-249.

Pressley, M., Levin, J. R., \& Ghatala, E. S. (1984). Memory strategy monitoring in adults and children. Journal of Verbal Learning \& Verbal Behavior, 23, 270-288.

Pressley, M., Snyder, B. L., Levin, J. R., Murray, H. G., \& GhaTALA, E. S. (1987). Perceived readiness for examination performance (PREP) produced by initial reading of text and text containing adjunct questions. Reading Research Quarterly, 22, 219-236.

Rabinowitz, J. C., Ackerman, B. P., Craik, F. I. M., \& Hinchley, J. L. (1982). Aging and metamemory: The roles of relatedness and imagery. Journal of Gerontology, 37, 688-695.

REDER, L. M. (1996). Implicit memony and metacognition. Mahwah, NJ: Erlbaum.

Reder, L. M., \& SchunN, C. D. (1996). Metacognition does not imply awareness: Strategy choice is governed by implicit learning and memory. In L. M. Reder (Ed.), Implicit memory and metacognition (pp. 45-78). Mahwah, NJ: Erlbaum.

SCHNEIDER, W. (1988). Micro Experimental Laboratory (Version 1.0) [Computer software]. Pittsburgh: Psychological Software Tools.

Schraw, G., Dunket, M. E., Bendixen, L. D., \& Roedel, T. D (1995). Does a general monitoring skill exist? Journal of Educational Psychology, 87, 433-444.

Schraw, G., Potenza, M., \& Nebelsick-Gullet, L. (1993). Constraints on the calibration of performance. Contemporary Educational Psychology, 18, 455-463.

SCHRAW, G., \& RoEDEL, T. D. (1994). Test difficulty and judgment bias. Memory \& Cognition, 22, 63-69.

SChWARTZ, B. L. (1994). Sources of information in metamemory: Judgments of learning and feelings of knowing. Psychonomic Bulletin \& Review, 1, 357-375

Schwartz, B. L., \& Metcalfe, J. (1994). Methodological problems and pitfalls in the study of human metacognition. In J. Metcalfe \& A. P. Shimamura (Eds.), Metacognition: Knowing about knowing (pp. 93-113). Cambridge, MA: MIT Press.

Slife, B. D., \& Weaver, C. A., III. (1992). Depression, cognitive skill, and metacognitive skill in problem solving. Cognition \& Emotion, 6 , $1-22$.

Spellman, B. A., \& BJork, R. A. (1992). When predictions create reality: Judgments of learning may alter what they are intended to assess. Psychological Science, 3, 315-316

ThiEde, K. W., \& Dunlosky, J. (1994). Delaying students' metacognitive monitoring improves their accuracy in predicting their recognition performance. Journal of Educational Psychology, 86, 290-302.

ThOMPSON, W. B., \& MASON, S. E. (1996). Instability of individual differences in the association between confidence judgments and memory performance. Memory \& Cognition, 24, 226-234.

UNDERWOOD, B. J. (1966). Individual and group predictions of item difficulty for free learning. Journal of Experimental Psychology, 71, 673-679.
WaLCZyK, J. J., \& HAI.L, V. C. (1989). Is the failure to monitor comprehension an instance of cognitive impulsivity? Journal of Educational Psychology, 81, 294-298.

WEAVER, C. A., III (1990). Constraining factors in calibration of comprehension. Journal of Experimental Psychology: Learning, Memory, \& Cognition, 16, 214-222.

Weaver, C. A., III, \& Bryant, D. S. (1995). Monitoring of comprehension: The role of text difficulty in metamemory for narrative and expository text. Memory \& Cognition, 23, 12-22.

Weaver, C. A., III, Bryant, D. S., \& Burns, K. D. (1995). Comprehension monitoring: Extensions of the Kintsch and van Dijk model. In C. A. Weaver, III, S. Mannes, \& C. R. Fletcher (Eds.), Discourse comprehension: Essays in honor of Walter Kintsch (pp. 177-193). Hillsdale, NJ: Erlbaum.

WEAVER, C. A., III, \& Kelemen, W. L. (1997). Judgments of learning at delays: Shifts in response patterns or increased metamemory accuracy? Psychological Science, 8, 318-321.

WELLMAN, H. M. (1978). Knowledge of the interaction of memory variables: A developmental study of metamemory. Developmental Psychology, 14, 24-29.

WRIGHT, D. B. (1996). Measuring feeling of knowing. Applied Cognitive Psychology, 10, 261-268.

YATES, J. F. (1990). Judgment and decision making. Englewood Cliffs, NJ: Prentice-Hall.

YUSSEN, S. R., \& LEVY, V. M. (1975). Developmental changes in predicting one's own span of short-term memory. Journal of Experimental Child Psychology, 19, 502-508.

\section{NOTES}

1. $G$ correlations range from -1.0 (perfect negative correlation) to +1.0 (perfect positive correlation), with 0 representing complete lack of predictive accuracy. Unlike other correlation coefficients, $G$ is not interpreted in terms of variance accounted for, but rather has a probabilistic interpretation. Specifically, if an individual gives two items different JOLs and only one of these items is correctly recalled, the probability $(P)$ that the correct item was given a higher $\mathrm{JOL}$ is determined by the equation: $P=0.5+0.5 G$

2. This dichotomy is somewhat contrived, because "state" and "trait" explanations are not mutually exclusive. Nevertheless, these terms have an intuitive appeal and we view them as a useful framework for past findings. Metacognitive accuracy could still be affected by temporary states even if reliable individual differences (traits) are observed. We thank Asher Koriat for pointing this out.

3. Patton, Weaver, Burns, Brady, and Bryant (1991) failed to replicate this finding in adult college students.

4. We used proportion correct as the dependent variable for all memory tasks. However, memory accuracy in EOL paradigms can also be expressed as the number of trials to learn each paired associate. This yields a more sensitive index of performance because the trials-to-learn criterion results in a range of values rather than the binomial outcome derived by examining recall on the first test. We also believe that the trials-to-learn criterion is more consistent with the EOL prediction we asked participants to provide. These two dependent variables are inversely related: Better EOL performance is characterized by fewer trials to learn, but higher proportion correct on the first test. Pearson correlations between the values derived from the two scoring methods were -.79 or stronger in this experiment $(p<.05)$. Therefore, we used the trials-to-learn criterion to compute $G$ between predictions and performance. In order to facilitate comparisons between $\mathrm{OOL}$ and the other three tasks, the sign of EOL values was reversed whenever the trials-tolearn criterion scoring method was used. The computational procedures for discrimination scores, however, required that the proportion of items correct on the first test be used. Similar patterns of results were obtained despite this methodological difference. 
APPENDIX A

Descriptive Statistics for Bias and Discrimination Scores in Experiments 1 and 2

\begin{tabular}{|c|c|c|c|c|}
\hline \multirow[b]{2}{*}{ Measure and Condition } & \multicolumn{2}{|c|}{ Session 1} & \multicolumn{2}{|c|}{ Session 2} \\
\hline & $M$ & $S D$ & $M$ & $S D$ \\
\hline \multicolumn{5}{|c|}{ Experiment 1} \\
\hline \multicolumn{5}{|c|}{ Bias (confidence - accuracy) } \\
\hline EOL & -.22 & .03 & -.22 & .03 \\
\hline JOL-immediate & .06 & .04 & -.02 & .03 \\
\hline JOL-delayed & -.01 & .02 & -.04 & .03 \\
\hline FOK & -.05 & .02 & -.05 & .02 \\
\hline $\mathrm{TCM}$ & .01 & .02 & -.02 & .02 \\
\hline \multicolumn{5}{|l|}{ Discrimination } \\
\hline EOL & .13 & .02 & .04 & .02 \\
\hline JOL-immediate & .14 & .02 & .11 & .02 \\
\hline JOL-delayed & .47 & .04 & .45 & .03 \\
\hline FOK & N/A & & $\mathrm{N} / \mathrm{A}$ & \\
\hline TCM & $\mathrm{N} / \mathrm{A}$ & & $\mathrm{N} / \mathrm{A}$ & \\
\hline \multicolumn{5}{|c|}{ Experiment 2} \\
\hline \multicolumn{5}{|c|}{ Bias (confidence - accuracy) } \\
\hline EOL & -.17 & .02 & -.12 & .03 \\
\hline JOL & .11 & .03 & .08 & .03 \\
\hline FOK & -.04 & .02 & -.02 & .02 \\
\hline TCM & -.10 & .02 & -.10 & .02 \\
\hline \multicolumn{5}{|l|}{ Discrimination } \\
\hline EOL & .11 & .02 & .09 & .02 \\
\hline JOL & .11 & .02 & .12 & .01 \\
\hline FOK & .10 & .02 & .09 & .01 \\
\hline TCM & .01 & .01 & .02 & .01 \\
\hline
\end{tabular}

Note-The mean proportion of items correct on the first test trial was used to compute bias and discrimination scores in the EOL condition. Bias was computed for each participant by subtracting mean memory recall from mean confidence. Discrimination scores represent the difference between mean confidence for items answered correctly and mean confidence for items answered incorrectly. N/A, a cell entry could not be computed (see text for details). EOL, easy of learning; JOL, judgment of learning; FOK, feeling of knowing; TCM, text comprehension monitoring.

APPENDIX B

Spearman $r$ Correlations Between Bias Scores (Above the Main Diagonal) and Discrimination Scores (Below the Main Diagonal) in Experiment 1

\begin{tabular}{lcccccccc}
\hline & EOL1 & EOL2 & JOL-I1 & JOL-I2 & JOL-D1 & JOL-D2 & TCM1 & TCM2 \\
\hline EOL1 & 1.0 & $.44 \dagger$ & .26 & .21 & $.38 \dagger$ & .21 & .15 & .18 \\
EOL2 & .22 & 1.0 & $.46 \dagger$ & $.46 \dagger$ & $.27^{*}$ & $.52 \dagger$ & $.31^{*}$ & $.31^{*}$ \\
JOL-I1 & -.07 & $.31^{*}$ & $\mathbf{1 . 0}$ & $.52 \dagger$ & $.53 \dagger$ & $.52 \dagger$ & .13 & $.33^{*}$ \\
JOL-12 & $.30^{*}$ & .02 & .05 & 1.0 & $.27^{*}$ & $.43 \dagger$ & .24 & $.34 \dagger$ \\
JOL-D1 & .06 & $.29^{*}$ & $.45 \dagger$ & .13 & 1.0 & $.58 \dagger$ & .10 & .20 \\
JOL-D2 & .20 & -.03 & .15 & .22 & .16 & 1.0 & .23 & $.38 \dagger$ \\
TCM1 & N/A & N/A & N/A & N/A & N/A & N/A & 1.0 & $.25 *$ \\
TCM2 & N/A & N/A & N/A & N/A & N/A & N/A & N/A & 1.0 \\
\hline
\end{tabular}

Note-Correlations of bias scores appear above the main diagonal; correlations of discrimination scores are below the main diagonal. N/A, correlation could not be computed (see text for details). Correlations between sessions, but within a particular metacognitive task condition, are shown in boldface for ease of comparison. EOL, ease of learning; JOL, judgment of learning; TCM, text comprehension monitoring. ${ }^{*} p<.05 ; \quad{ }^{\dagger} p<.01$. 


\section{APPENDIX C}

Spearman $\boldsymbol{r}$ Correlations Between Bias Scores (Above the Main Diagonal) and Discrimination Scores (Below the Main Diagonal) in Experiment 2

\begin{tabular}{lcccccccc}
\hline & EOL1 & EOL2 & JOL1 & JOL2 & FOK1 & FOK2 & TCM1 & TCM2 \\
\hline EOL1 & 1.0 &. $\mathbf{3 6}$ & $.25^{*}$ & $.42 \dagger$ & $.24^{*}$ & $.24^{*}$ & $.27^{*}$ & $.25^{*}$ \\
EOL2 &. $\mathbf{1 9}$ & 1.0 & $.28^{*}$ & $.48^{\dagger}$ & .04 & $.27^{*}$ & .21 & $.26^{*}$ \\
JOL1 & -.14 & .07 & 1.0 & $.57 \dagger$ & $.43 \dagger$ & $.39 \dagger$ & $.42 \dagger$ & $.50 \dagger$ \\
JOL2 & .07 & -.23 & .02 & 1.0 & $.24^{*}$ & $.34 \dagger$ & $.39 \dagger$ & $.42 \dagger$ \\
FOK1 & .23 & -.03 & -.04 & -.22 & 1.0 &. $\mathbf{4 0} \dagger$ & $.26^{*}$ & .20 \\
FOK2 & .16 & -.03 & -.02 & -.15 & .19 & 1.0 & .21 & $.36 \dagger$ \\
TCM1 & .18 & -.03 & -.19 & .07 & -.05 & .08 & .1 .0 & $.44 \dagger$ \\
TCM2 & .01 & .08 & -.10 & -.11 & -.13 & -.01 & -.02 & 1.0 \\
\hline
\end{tabular}

Note-Correlations of bias scores appear above the main diagonal; correlations of discrimination scores are below the main diagonal. Correlations between sessions, but within a particular metacognitive task condition, are shown in boldface for ease of comparison. EOL, ease of learning; JOL, judgment of learning; FOK, feeling of knowing; TCM, text comprehension monitoring. ${ }^{*} p<.05 ; \quad{ }^{\dagger} p<.01$.

(Manuscript received February 9, 1999; accepted for publication February 9, 1999.) 